\section{Catherine Magnant: Hay que fomentar que los trabajos relacionados con el patrimonio sean de calidad, evitando cualquier tipo de especulación o precarización}

URL de la contribución <www.iaph.es/revistaph/index.php/revistaph/article/view/4127>

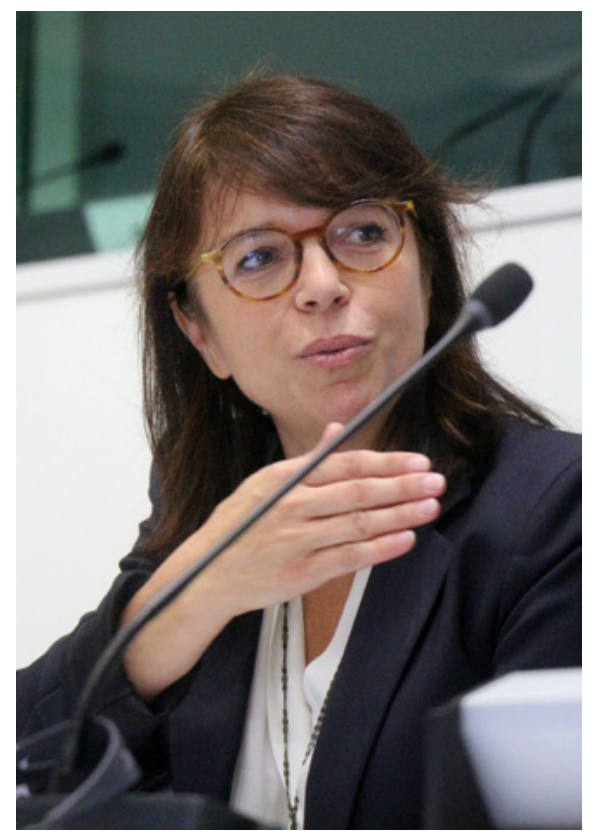

Catherine Magnant | foto Comisión Europea
En mayo de 2017 la Comisión Europea declaraba 2018 como "Año Europeo del Patrimonio Cultural" (EYCH, siglas en inglés). Este año, tal y como se justifica en la misma declaración, tiene una importancia simbólica e histórica para Europa y su patrimonio cultural, al conmemorar una serie de acontecimientos significativos, como el centenario del final de la Primera Guerra Mundial y la independencia de varios Estados miembros, así como el cuarto centenario del inicio de la Guerra de los Treinta Años.

Catherine Magnant, de nacionalidad francesa y graduada en relaciones internacionales y lenguas eslavas, dirige el grupo ejecutivo para hacer realidad esta conmemoración. Actual consejera de la unidad de Cultura y Creatividad de la Dirección General de Educación, Juventud, Deporte y Cultura de la Comisión Europea, Catherine cuenta con experiencia en la organización de eventos conmemorativos de esta magnitud. En 2007 coordinó el Año europeo de la igualdad de oportunidades para todos; entonces formaba parte de la Dirección General de Empleo y Asuntos Sociales de la misma Comisión. Desde su establecimiento en Bruselas, la labor de Catherine en este organismo, que comenzó en 1996 como responsable de prensa e información en la delegación local de Moscú, ha estado muy ligada a la promoción de los derechos humanos y la lucha contra la discriminación. Inspira su trabajo ahora en la Comisión los principios que rigen los objetivos del Año Europeo del Patrimonio Cultural 2018: concienciar de que "el patrimonio cultural no es sólo un legado del pasado, es también un recurso impresicindible para nuestro futuro, dado su incuestionable valor educativo y social, su considerable potencial económico, así como su importante dimensión en cooperación internacional". 
revista ph: ¿Cómo se articulará, en líneas generales, el Año Europeo del Patrimonio? ¿A través de qué proyectos y programas?

El Año Europeo del Patrimonio Cultural, en primer lugar, pretende marcar una línea clara de colaboración de todas las instituciones y organizaciones cuyo ámbito de acción es el patrimonio en un sentido amplio. Por ello nuestra labor principal es coordinar esta red y hacer que funcione desde un nivel local y regional a uno más amplio nacional y europeo. Desde el equipo de trabajo en la Comisión Europea nos hacemos cargo del nivel europeo, mientras que los coordinadores nacionales designados por cada país se encargan del ámbito nacional y sus contactos con instituciones regionales y locales.

A todo ello, además, hay que unir una vocación marcadamente internacional que sobrepasa las propias fronteras de los países integrantes de la Unión. Contamos para lograr estos objetivos con el apoyo de las delegaciones de la Unión Europea en el mundo y de organizaciones internacionales como la UNESCO y el Consejo de Europa.

No obstante, existe un gran número de iniciativas y programas que recaen directamente en la responsabilidad de la Comisión y que en el marco del Año serán resaltadas (tenemos buenos ejemplos con el Sello de Patrimonio Europeo y las Jornadas Europeas del Patrimonio). Además, hemos lanzado un llamamiento especial de proyectos asociados al Año por parte del programa Europa Creativa, un programa marco de la Comisión Europea que viene apoyando la financiación de proyectos creativos y culturales con gran éxito. Otro elemento clave ha sido el lanzamiento de una campaña de comunicacion que incluye una identidad visual para el Año, website, presencia en redes sociales, videos promocionales, boletines informativos bimensuales, etc., para tratar de aumentar la visibilidad de las iniciativas al máximo.

Por otro lado, desde la Comisión Europea se han marcado cuatro pilares básicos con los que trabajar: compromiso; sostenibilidad; protección e innovación. De ellos emanan nuestras diez iniciativas a implementar durante el año.
El objetivo de todo ello es, por un lado, despertar el interés por el patrimonio en la ciudadanía; y, por otro, desarrollar unos métodos de trabajo a largo plazo en los que destaque la calidad, la protección, la innovación tecnológica y la puesta en valor del patrimonio como recurso sostenible y que genera riqueza, cohesión e identidad. Evidentemente se pretende crear un legado que supere a la propia celebración anual y funcione a más largo plazo.

revista ph: El Año Europeo del Patrimonio Cultural (Año Europeo en lo sucesivo) tiene como uno de sus objetivos prioritarios fomentar el intercambio y la valoración del patrimonio de Europa como un recurso compartido con el deseo de reforzar el sentimiento de pertenencia al espacio común europeo. Un sentimiento de pertenencia que se propone la UE desde hace décadas y que no acaba de conseguirse. ¿A qué cree que se debe? ¿Puede realmente el patrimonio cultural contribuir a mejorar esta situación?

Realmente así lo creemos y debemos trabajar para ello. Los resultados del último eurobarómetro sobre "los europeos y el patrimonio" así nos lo muestran, por lo que debemos ser optimistas. Los europeos valoran su patrimonio y se sienten orgullosos de él. Más del $80 \%$ cree que el patrimonio es muy importante para la UE; mientras que el $68 \%$ afirma que quiere conocer más sobre él.

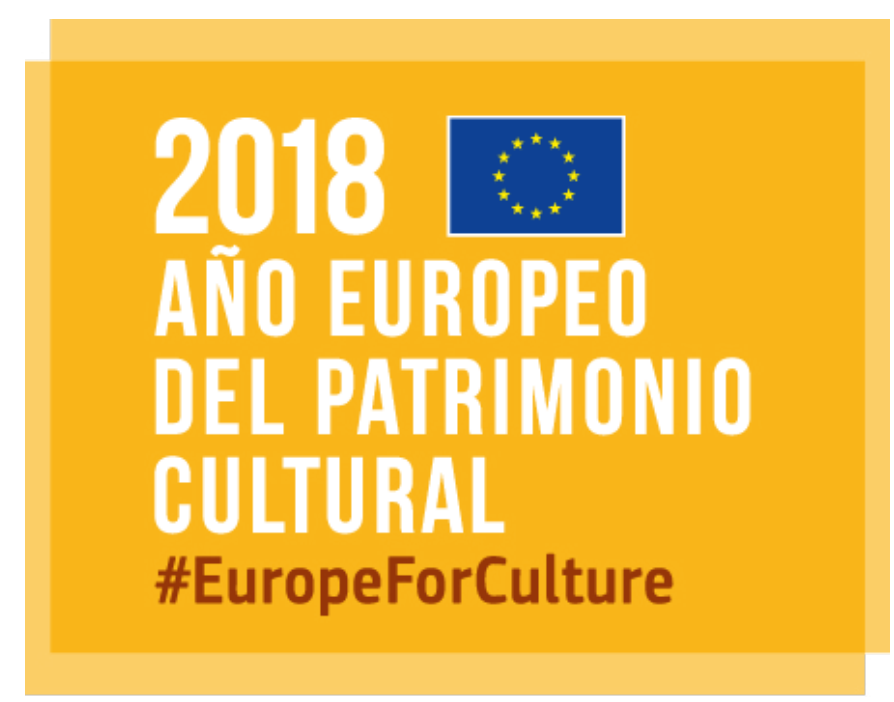


Incluso un $70 \%$ de los ciudadanos europeos dice sentirse orgulloso de elementos patrimoniales europeos que pertenecen a otro país diferente al suyo. Los datos son muy positivos. Hay inquietud y deseo de conocimiento por parte de la ciudadanía, por lo que partimos de buenos mimbres.

Además, en los últimos tiempos, en la propia Unión Europea vemos un claro cambio de tendencia que lleva a prestar una mayor atención a la educación y la cultura. El hecho de que 2018 haya sido designado como el Año Europeo del Patrimonio Cultural es una prueba clara. Ésta es, sin duda, una buena señal. Parece claro que el conocimiento y la valoración del patrimonio es positivo para la sociedad, es un hecho innegable. Por ello es bueno que se concentren los esfuerzos en crear una unión no solo vinculada a intereses políticos y económicos, sino también culturales. El patrimonio hay que cuidarlo, no se mantiene vivo y en pie sin un poco de esfuerzo por parte de todos.

revista ph: ¿Cómo se conjuga la conciencia de un patrimonio común que genere sentimiento de pertenencia europeo con la puesta en valor y protección de la diversidad cultural?

La diversidad es fundamental. Cualquier persona que tenga un mínimo conocimiento histórico, artístico o cultural puede percibir que ninguna época ni estilo artístico son simples ni unitarios, ni se han generado de la nada o de forma aislada. El patrimonio es precisamente eso: una recogida e intercambio constante de información que permite en última instancia la creación y desarrollo de la arquitectura, la lengua, la danza, la música, la artesanía... El patrimonio no sabe de fronteras.

El Año Europeo tiene intención de remarcar esta condición e incluir a todos los ciudadanos. Todos somos partícipes y vivimos experiencias, digamos, patrimoniales, en nuestro día a día. Desde nuestro modo de cocinar a nuestro modo de hablar. No se trata por tanto en ningún caso de la celebración de un tipo de cultura sobre otra, muy al contrario, es la puesta en valor de la complejidad del patrimonio en todas sus vertientes, tangibles e intangibles, desde los monumentos más conocidos a los más pequeños detalles que pasan inadvertidos y forman parte también del patrimonio.

La intención es generar un caldo de cultivo, ayudar a que sea la propia ciudadanía la que se percate de este valor.

revista ph: En la declaración del Año Europeo el concepto de gobernanza participativa está presente, articulada por la cooperación activa de diferentes agentes sociales en su organización y toma de decisiones. Por ejemplo, además de la implicación de los Estados miembros y administraciones públicas a distintos niveles, la Comisión tiene prevista recabar la ayuda en la puesta en práctica del Año Europeo de organizaciones entidades activas en el ámbito del patrimonio cultural, incluidas las redes transnacionales existentes y las ONG relevantes, además de organizaciones juveniles y del sector del voluntariado. ¿Cómo se articula esta participación en un marco geográfico tan amplio? ¿Nos lo puede mostrar con algún ejemplo práctico?

Es una labor compleja, evidentemente, al tratarse de un marco geográfico muy extenso y con muchas diferencias. Sin embargo, desde la Comisión estamos habituados a este hecho, y la colaboración con estados y asociaciones forma parte de nuestro día a día.

Es importante recordar que el Año Europeo es una iniciativa descentralizada, donde los Estados miembros tienen un rol protagonista, y la Comisión tiene un rol de soporte y coordinación.

Trabajamos con una red de coordinadores nacionales, designados por Estados miembros, y de asociaciones de la sociedad civil y sector profesional que nos hacen llegar la información de forma rápida y fluida. Con ellos estamos en contacto permanente y tenemos reuniones periódicas. Además, dentro de la Comisión, diferentes departamentos están implicados, desde aquellos trabajando en desarrollo regional, pasando por investigación e innovación o empleo. A ello hay que unir las representaciones en los diferentes países y el trabajo de las instituciones europeas; el Parlamento, el Consejo, el Comité Europeo de las Regiones y el Comité Económico y Social Europeo. Con todo ello podemos decir que abarca- 


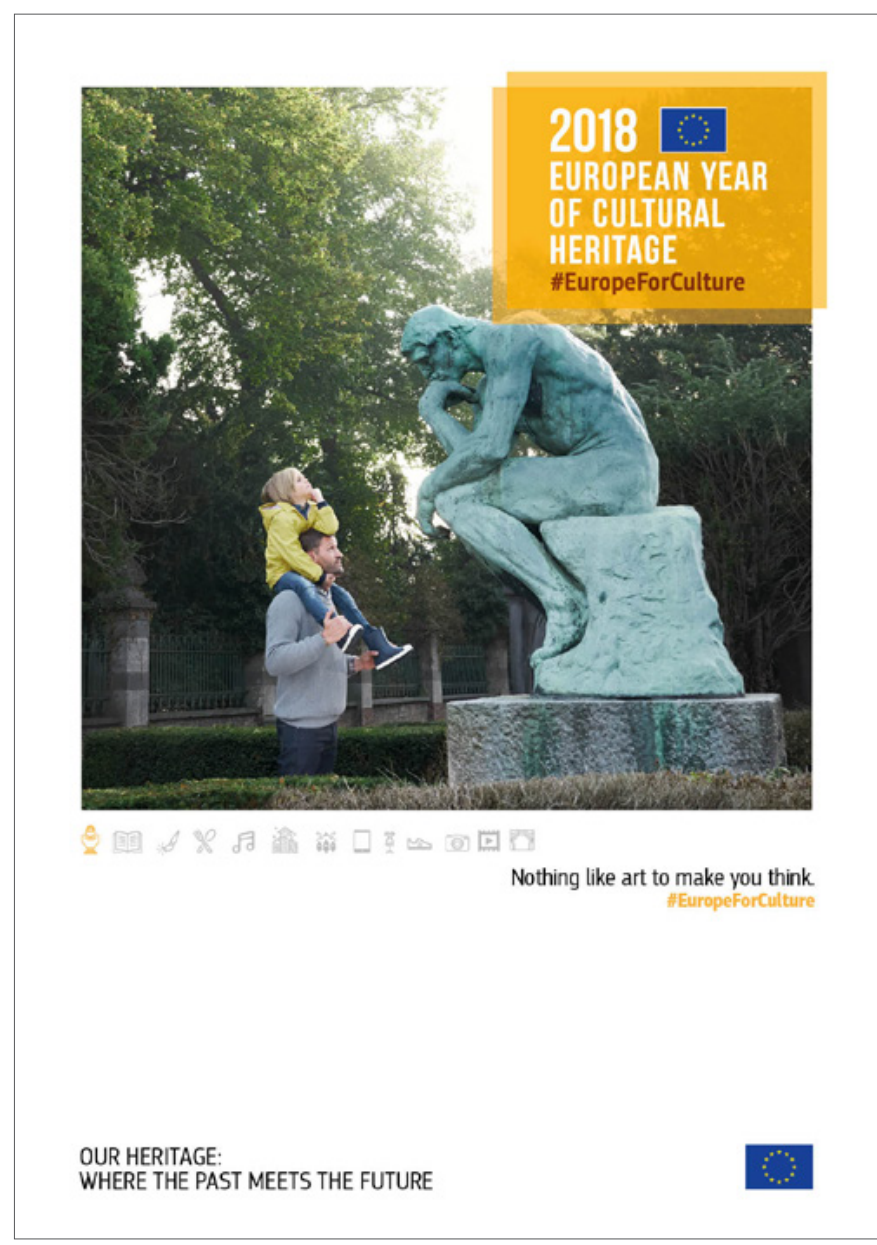

mos eficientemente todo el marco geográfico europeo a muy diversos niveles.

Además, hemos estado trabajando especialmente en el concepto de gobernanza participativa y la innovación social. Una de nuestras iniciativas durante el Año está expresamente dedicada a esta cuestión. Es importante encontrar y analizar ejemplos de buenas prácticas en la implicación ciudadana que puedan ser extendidas a otros lugares. Con ello esperamos fomentar un desarrollo transversal que convierta a las comunidades en un elemento activo en el trabajo con el patrimonio. Para ello contamos con proyectos de investigación y plataformas apoyados por el programa H2020 (Horizonte 2020, el programa marco de investigación e innovación de la UE) y el Consejo Europeo. revista ph: Otra clara apuesta del Año Europeo es el apoyo a las industrias creativas, partiendo de la consideración de la conexión existente entre creación artística contemporánea, patrimonio cultural, innovación y la emergencia de nuevas oportunidades de negocio. Prueba de ello es la dotación con 5 millores de euros (de los 8 que contempla el presupuesto total destinado al Año Europeo) al programa europeo de cultura "Europa Creativa" para proyectos que se sustenten en la cooperación entre el sector creativo y patrimonial que respondan a los objetivos del Año Europeo. El 22 de noviembre de 2017 acababa el plazo de presentación de proyectos. ¿Qué tipo de proyectos han sido seleccionados?

Debo aclarar que los proyectos aún no han sido seleccionados, por lo que no puedo adelantar detalles. En todo caso el eslogan lo dice claramente: el pasado y el futuro se complementan. No se trata tan sólo de preservar lo heredado, sino de fomentar la creación artística y patrimonial que nosotros legaremos a las futuras generaciones. Todo se complementa, no se crea de la nada. Hay por tanto una relación clara de los nuevos proyectos con las artes y tradiciones anteriores.

Los proyectos seleccionados en años anteriores nos dan una idea de la variedad de sus orientaciones: abarcan todo tipo de patrimonio, material e inmaterial, desde la artesanía, las artes plásticas y la conservación, a las nuevas innovaciones tecnológicas y el ámbito más estrictamente digital.

En todo caso en las bases de la convocatoria se avisa que los proyectos deben estar orientados a la creación colectiva como método de refuerzo del sentimiento de espacio compartido, así como a la utilización del patrimonio como inspiración para la creación contemporánea.

No obstante hay que permanecer atentos durante el año y ver cómo se desarrollan durante los meses venideros, el Año no ha hecho más que comenzar.

revista ph: Pero el potencial económico del patrimonio cultural europeo en relación con las industrias creativas, bajo una lógica de mercado como la que impera, ¿pueden suponer algún riesgo para el patrimonio cultural? 


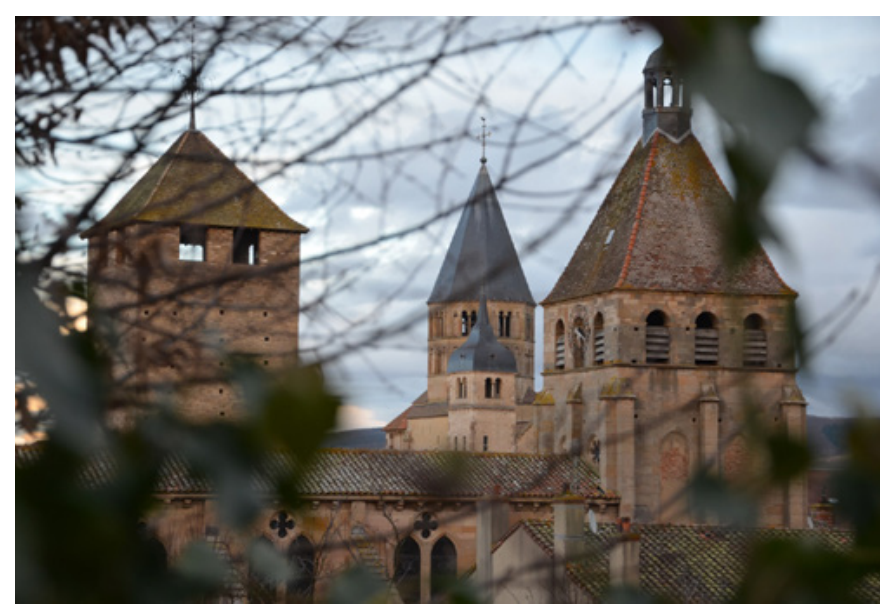

Abadía de Cluny (Francia) | foto Luc Dumoulin

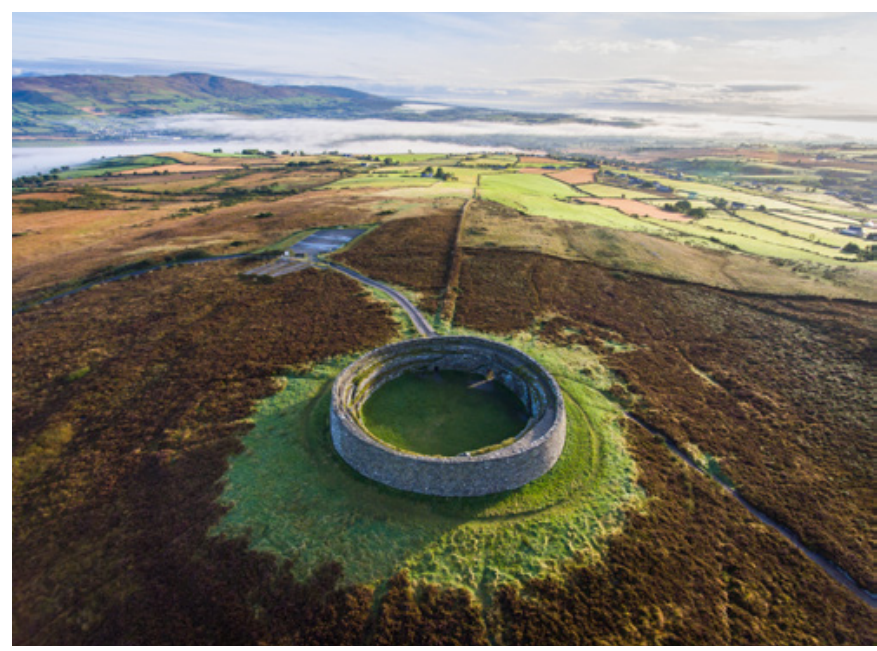

Grianán de Ailech (condado de Donegal, Irlanda) | foto EYCH Photobank

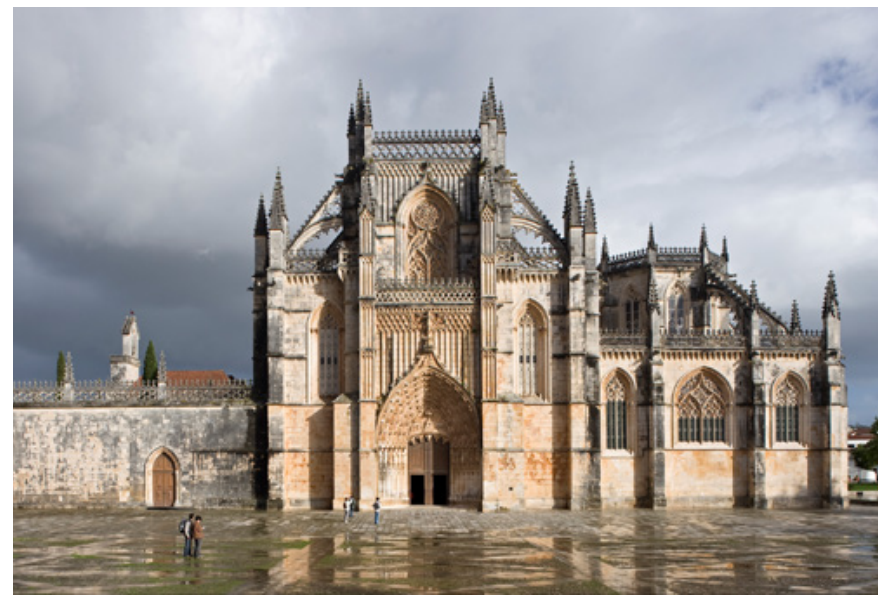

Monasterio de Batalha (Portugal) | foto DGPC
Siempre ha habido un recelo a este hecho por parte de ciertos sectores, hasta cierto punto lógico, pero no tendría por qué ser así. Es un hecho, y los datos son claros al respecto, que el patrimonio genera riqueza y que un enorme número de puestos de trabajo en Europa, de forma directa o indirecta, están asociados al mismo. Negar eso sería negar la evidencia. Sabemos que son 300.000 los trabajadores cuyo empleo está directamente relacionado con el patrimonio cultural en Europa. Si a ello sumamos los trabajos que se crean de un modo indirecto en relación con el patrimonio, la cifra alcanza una cifra cercana a los 8 millones de personas (Cultural Heritage counts for Europe Report, 2016).

Creemos que en vez de actuar a la defensiva hay que hacer precisamente lo contrario, valorar esta posición y trabajar desde ella para que realmente sea un recurso efectivo de mejora social. Debemos fomentar la industria cultural en el sentido de que es una industria limpia y sostenible.

Evidentemente hay que velar porque las actuaciones relacionadas con el patrimonio sean respetuosas y que estén dedicadas al bien de la comunidad en que se inscriben. Hay leyes y recomendaciones claras al respecto $y$, lógicamente, debemos seguir trabajando para que sean respetadas en todo momento.

Del mismo modo hay que fomentar que los trabajos relacionados con el patrimonio sean de calidad, evitando cualquier tipo de especulación o precarización.

Por encima de todo hay que ser optimistas, el patrimonio es un bien común, y las instituciones tenemos que trabajar para que ese bien revierta en toda la sociedad de forma justa y equitativa.

revista ph: El potencial económico del patrimonio cultural también está asociado a su explotación como recurso turístico. La Comisión Europea cuenta con el programa del Sello de Patrimonio Europeo o el de Capitales Europeas de la Cultura, por ejemplo, que contribuyen a incorporar espacios geográficos en la red de destinos turísticos. A pesar de que las políticas se implementan bajo la premisa del desarrollo sostenible (como reconoce la 
Agenda 2030 de la ONU), vivimos un proceso de terciarización de las ciudades derivado del auge del turismo cultural que conlleva otros procesos de revalorización del suelo y sustitución social de los habitantes (gentrificación) ¿Cómo podemos superar esta contradicción?

Sin duda es un tema complicado y que tiene que ver con múltiples factores y sectores que superan al propio patrimonio y su gestión.

Iniciativas como el Sello de Patrimonio Europeo o las Capitales Europeas de la Cultura tienen poco que ver con el problema de la gentrificación. De hecho tratan de poner en valor lugares, y no sólo lugares, también documentos y otro tipo de valores intangibles, que hay que conocer y preservar, pero que están lejos de la masificación. Precisamente fomentar el respeto y el conocimiento del patrimonio en un sentido amplio y diversificado es una buena medida para combatir un tipo de turismo masivo que sólo acude a unos pocos lugares de ciertas capitales (Barcelona, París, Roma...). Hay muchos otros lugares que merecen ser conservados $y$, por qué no, también visitados. Pero desde el respeto y la sostenibilidad.

Creo que se está trabajando en la buena dirección. Señalar la importancia real, histórica, social, artística y cultural, de sitios desconocidos por el gran público puede ser una manera de contribuir a generar unos movimientos turísticos más fluidos y beneficiosos para las comunidades que habitan las ciudades. De este modo se evita la masificación y se reparten de modo más equilibrado los beneficios.

Los ciudadanos quieren que sus pueblos, ciudades o paisajes sean valorados y visitados, se sienten orgullosos de ello, no hay por qué huir de eso.

Tengo que añadir además que otra de las iniciativas del año está dedicada al desarrollo de un turismo sostenible. Por ello, desde este grupo de trabajo, podemos decir que estamos desarrollando una rigurosa investigación. En primer momento identificando buenas prácticas que se han venido desarrollando en estos últimos tiempos. Aunque se trata de un trabajo en pleno proceso de realización, tendrá sus primeros frutos a finales de año, cuando se harán públicos sus resultados y las recomendaciones que servirán de soporte a las instituciones y organizaciones, a nivel local, regional, nacional y europeo, que trabajan en este ámbito.

revista ph: El Año Europeo del Patrimonio (2018), Año Europeo de la igualdad de oportunidades para todos (2007), Año Europeo del Envejecimiento Activo y de la Solidaridad Internacional (2012)... por citar algunos. Desde su experiencia, ¿cree que son importantes este tipo de conmemoraciones? ¿por qué? ¿Qué llega al ciudadano de a pie?

Son importantes, muy importantes, claro. Qué puedo decir yo...

Fuera de bromas, no se trata ya solo de una celebración, sino de dar visibilidad a ciertos aspectos sociales o culturales que, en algunos casos, pasan desapercibidos. Es una buen manera de generar debate, discusión, reflexión... Hacer énfasis en ellos es siempre positivo. Además está demostrado que este tipo de iniciativas superan su propio marco temporal anual y marcan una tendencia beneficiosa en el sector a medio y largo plazo.

Es todo un reto llegar a los casi 500 millones de habitantes europeos. A ellos se dirigen un enorme número de iniciativas que permean a todos los niveles, incluso a un nivel local y comunitario muy específico de otro modo muy difícil de alcanzar. De entre ellas tenemos destacados ejemplos, como las Jornadas Europeas del patrimonio, que se celebran en septiembre y que consiguen la participación de más de 30 millones de ciudadanos.

En todo caso, invito a todos a permanecer atentos y disfrutar de la cultura y el patrimonio durante todo este año. Es muy probable que después de haberlo hecho así se convierta en un nuevo hábito, consciente o inconsciente, en nuestras vidas. Y ese es un enorme avance.

Quizás debiéramos volver a vernos al final de año otra vez para poder valorarlo entonces.

Muchas gracias. 